\title{
FORTALEZA DA DESIGUALDADE E VIOLÊNCIA: GEOPOLÍTICA DO MEDO E ANOMIA SOCIAL COMO FATOR DE PRODUÇÃO DA VIOLÊNCIA CONCENTRADA E DA SENSAÇÃO DE INSEGURANÇA
}

\section{${ }^{1}$ Laecio Noronha Xavier}

\section{RESUMO}

Fortaleza/Ceará é a $5^{\mathrm{a}}$ cidade brasileira em demografia e $10^{\mathrm{a}} \mathrm{em}$ PIB. Todavia, é a quinta cidade mais desigual do mundo e sua taxa de homicídios tornou-a na capital mais violenta do Brasil, e segunda cidade em número de homicídios no mundo. Entre 2007-2014, Fortaleza vivenciou quase um retorno ao estado de natureza com vitimização preferencial dos homens jovens e negros. Geopoliticamente, o medo e a anomia têm aprisionado seus habitantes em uma cidade dos muros, alimentado a violência, expandido a sensação de insegurança e atuado contra as populações periféricas.

Palavras-chave: Geopolítica do Medo, Violência Concentrada, Sensação de Insegurança

\section{FORTALEZA DE LA DESIGUALDAD Y LA VIOLENCIA: GEOPOLÍTICA DEL MIEDO Y LA ANOMIA SOCIAL COMO FACTOR DE PRODUCCIÓN DE LA VIOLENCIA CONCENTRADA Y DE LA SENSACIÓN DE INSEGURIDAD}

\section{RESUMEN}

Fortaleza/Ceará es la $5^{\mathrm{a}}$ ciudad en la demografía y $10^{\mathrm{a}}$ en el PIB. Sin embargo, es la quinta ciudad más desigual del mundo y su tasa de homicidios se ha convertido en la capital más violenta de Brasil, y la segunda ciudad mundial en homicidios. Entre 2007-2014, experimentó casi un retorno al estado de naturaleza con la victimización preferida de los jóvenes y negros. Geopolíticamente, el miedo y la anomia han encarcelado a sus habitantes en una ciudad de las paredes, alimentado la violência y la sensación de inseguridad y ha actuado en contra de las poblaciones periféricas.

Palabras-claves: Geopolítica del Miedo, Violencia Concentrada, Sensación de Inseguridad

\footnotetext{
1 Doutor pela Universidade Federal de Pernambuco - UFPE, Pernambuco (Brasil). Coordenador do Curso de Direito Faculdade Luciano Feijão - FLF, Ceará (Brasil). E-mail: laecio.interagir@ibest.com.br
} 


\section{INTRODUÇÃO}

Fortaleza é a capital do Estado do Ceará, situado na região Nordeste do Brasil. Sua toponímia é uma alusão ao Forte Schoonenborch, construído pelos holandeses durante sua permanência no local entre 1649 e 1654, o qual deu origem ao município. Em Fortaleza, colonizada posteriormente por portugueses, o medo da violência está presente desde o batismo, no brasão, em que se vê o forte erguido com finalidade de debelar invasores externos e internos (piratas franceses, índios, retirantes), e no lema da cidade - Fortitudine - que em português significa "força". Contudo, com o passar dos séculos, os canhões do Forte Schoonemborch não apontavam para o litoral, de onde se esperava que chegassem os inimigos externos, mas para a própria Vila de Fortaleza. Enquanto histórico problema geopolítico, a posição dos canhões expressava o modo repressivo das autoridades em conter o descontentamento popular e intimidar as rebeliões internas.

No século XXI, Fortaleza apresenta-se como a quinta cidade brasileira em demografia e a cidade nordestina com maior área de influência econômica regional, sendo a primeira do Nordeste e a décima do Brasil em economia. Todavia, as temáticas centrais da cidade são a desigualdade e a violência, uma vez que os "canhões" continuam apontados para Fortaleza até o presente. Recentemente, Fortaleza foi identificada por organismos públicos e privados (internacionais/nacionais) como uma das cinco cidades mais desiguais do mundo, a capital mais violenta do Brasil e a segunda metrópole com maior número de homicídios do planeta. Entre 20072014, Fortaleza vivenciou um quase retorno ao "estado de natureza" em termos de aumento da violência, criminalidade e marginalidade, e paradoxalmente, a exemplo das unidades federativas do Brasil, com forte elevação do orçamento estadual em Segurança Pública e inclusão social de volumosos segmentos menos abastados economicamente.

Inicialmente, o artigo objetiva expor os dados gerais sobre a pujança econômica de Fortaleza, e paralelamente, os indicadores de desigualdade social e suas taxas recentes de criminalidade (2007-2014), uma nefasta combinação conjuntural que depõe contra a cidade no Brasil e no exterior. Posteriormente, discorre sobre a "geopolítica" e suas categorias, bem como conceitua sinteticamente violência, criminalidade, marginalidade, medo e anomia social. E no último tópico, verifica-se como a geopolítica do medo e anomia social tornou-se fator de produção da violência difusa e concentrada em determinados segmentos étnicos, sociais e urbanos, e generalizou a sensação social de insegurança na população, além das razões institucionais e consequências socioeconômicas da explosão da criminalidade em Fortaleza no período em face dos equívocos da Política de Segurança Pública.

A própria simbologia de Fortaleza per si justifica a temática acerca do crescimento abismal da violência na urbe: os canhões reais e imaginários que segregam socialmente a maioria de sua população e vitimizam preferencialmente os homens jovens, negros, pobres, de baixa renda, pouca 
formação escolar e moradores das periferias. Ademais, a abordagem da temática vem acrescida de categorias da Geopolítica como fundamento analítico sobre a adoção ou não de uma moderna concepção de Segurança Pública (Repressão Qualificada, Prevenção e Ressocialização) quando do exame dos conflitos criminais em Fortaleza. Entretanto, envolve em seu bojo não apenas práticas institucionais convencionais de violência e contra-violência ("monopólio legítimo da força”), uma vez que também diagnostica as condições socioeconômicas e a realidade urbana, fatores que podem estimular a produção da criminalidade territorial em determinada sociedade.

E sob o prisma da pesquisa metodológica, o artigo encontra-se ordenado nas seguintes etapas: i) Histórico-descritivo - dados gerais sobre Fortaleza e suas taxas de homicídios entre 20072014 em sua paradoxal vinculação com o aumento dos recursos orçamentários em Segurança Pública; ii) Sistêmico-conceitual - utilização da geopolítica e suas categorias e das bases conceituais de violência, criminalidade, marginalidade, medo e anomia social para análise da relação da Política de Segurança Pública e seus efeitos práticos em dado território jurisdicionado; iii) Analítico-interpretativo - razões doutrinárias e motivações gerenciais que ocasionaram os piores indicadores da Segurança Pública cearense e estruturação geopolítica da violência concentrada e da sensação social de insegurança. E no patamar das fontes de investigação, o artigo baliza-se em compêndios teóricos, estudos e documentos estatísticos de instituições públicas e privadas e pesquisas acadêmicas na área de Segurança Pública.

\section{FORTALEZA MARCADA PELA DESIGUALDADE SOCIAL E APRISIONADA PELA VIOLÊNCIA}

Conforme dados de 2014 do Instituto Brasileiro de Geografia e Estatística (IBGE), Fortaleza possui $314 \mathrm{~km}^{2}$ de área, $34 \mathrm{~km}$ de praias e 2.591 .188 habitantes, além da maior densidade demográfica entre as capitais brasileiras $\left(7.786 \mathrm{hab} / \mathrm{km}^{2}\right)$. É a maior cidade do Ceará e a $5^{\mathrm{a}}$ do Brasil em população, dentre os 5.570 municípios, ocupando a $174^{a}$ posição no ranking das maiores economias metropolitanas do mundo. A Região Metropolitana de Fortaleza é a $6^{\text {a }}$ mais populosa do Brasil e a $1^{\text {a }}$ do Nordeste, com 3.985.297 habitantes, sendo a $3^{\text {a }}$ região metropolitana mais rica das regiões Norte e Nordeste. Fortaleza é a cidade nordestina com a maior área de influência econômica regional atraindo 20 milhões de pessoas/ano e agrega a $3^{\text {a }}$ maior rede urbana do Brasil em população, atrás apenas de São Paulo e do Rio de Janeiro.

Fortaleza foi avaliada em 2015 como a $10^{a}$ cidade mais rica do país em Produto Interno Bruto (PIB) e primeira do Nordeste em economia, com $\mathrm{R} \$ 43$ bilhões. A cidade possui importante centro industrial e comercial do Brasil, com o oitavo maior poder de compra municipal da nação. No turismo, Fortaleza registra as marcas de segundo destino mais desejado do Brasil e $4^{\text {a }}$ cidade brasileira que mais recebe turistas (IBGE: 2014). Segundo dados do Programa das Nações Unidas para o Desenvolvimento (PNUD), de 2014, entre as 184 cidades do Ceará, Fortaleza obteve o 
maior Índice de Desenvolvimento Humano (IDH) com 0,754. E das 27 unidades federais, o Ceará alcançou somente o $17^{\circ} \mathrm{IDH}$, com 0,682. Para definir o IDH, o PNUD considera três indicadores variando de 0 a 1 (e quanto mais próximo de 1, melhor a avaliação): vida longa e saudável (longevidade), acesso ao conhecimento (educação) e padrão de vida (renda per capita).

Todavia, conforme dados do State of the world's cities 2010/2011: bridging the urban divide (Estado das Cidades do Mundo 2010/2011: Unindo o Urbano Dividido) do Programa das Nações

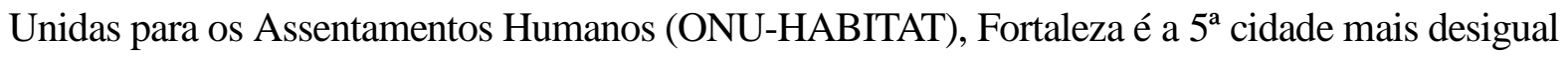
do mundo. Dos seus 120 bairros e 780.456 domicílios, apenas 422.702 domicílios acessam esgotamento sanitário, 709.687 possuem abastecimento de água, 700.786 apresentam coleta de lixo e 704.518 têm energia elétrica. E desses bairros, 92 aparecem com IDH relativo à renda como muito baixo (78,6\% do total), com os dez bairros de maior receita concentrando quase $1 / 3$ dos recursos da capital cearense $(31,6 \%)$. No IDH relativo à longevidade e educação, Fortaleza apresenta 88 bairros com índices extremamente baixos, e somente 03 bairros com índices muito altos. De acordo com o PNUD (2014), Fortaleza é apenas a 467ª cidade em IDH no Brasil $(0,754)$, representado pela renda $(0,749)$, longevidade $(0,824)$ e educação $(0,695)$.

Vale mencionar que o conceito de desigualdade social refere-se à falta de equilíbrio no padrão de vida dos habitantes de uma sociedade, ocasionado pelos desníveis econômicos, (distribuição heterogênea da renda), falta de investimentos privados e ineficiência das políticas sociais. A desigualdade social é uma porta para outros tipos de desigualdades (gênero, racial, econômica, urbana, regional), além de resultar em vários problemas urbanos, econômicos e sociais: favelização, atraso econômico, poucas oportunidades de emprego, miséria, baixo consumo de bens culturais, criminalidade, fome e falta de acesso aos serviços básicos (educação, saúde, transporte, saneamento). Neste sentido, se faz necessário o estudo científico da desigualdade social para lidar com a diversidade de foco na avaliação dos mecanismos geradores de outras desigualdades (SEN: 2001). Na "Fortaleza das desigualdades" a má distribuição de renda apresenta uma divisão geográfica: uma cidade rica e de primeiro mundo (Leste), e outra cidade pobre, violenta e precária em serviços públicos e investimentos privados (Oeste).

Ademais, como as grandes cidades brasileiras, Fortaleza padece de um quadro crítico de violência, tendo alcançado os posto de "capital mais violenta do Brasil" e segunda com maior número de homicídios no mundo. Em relação a 2014, a $9^{a}$ edição do Anuário Brasileiro de Segurança Pública (2015) do Fórum Brasileiro de Segurança Pública (FBSP) revelou que 58.559 pessoas foram assassinadas no País. É como se um brasileiro fosse morto a cada 10 minutos. A taxa de homicídio de 26,3 a cada 100 mil habitantes manteve o Brasil na lista dos 20 países mais violentos do mundo, sendo classificada como "tragédia civilizatória". Nas 27 capitais brasileiras, houve 15.932 homicídios em 2014 (uma vítima a cada 30 minutos). Juntas, as 27 capitais 
brasileiras registraram taxa média de 33 mortes violentas por 100 mil habitantes em 2014, com Fortaleza/CE apresentando os maiores índices proporcionais (77,3 a cada 100 mil habitantes) e absolutos de assassinatos (1.930), e São Paulo/SP, o menor indicador proporcional (11,4 a cada 100 mil habitantes). Como a Organização Mundial de Saúde (OMS) caracteriza os locais com índices iguais ou superiores a 10 homicídios para cada 100 mil habitantes enquanto "zonas endêmicas de violência", todas as capitais restam inclusas nesta classificação. (OMS: 2014).

A $9^{a}$ edição do Anuário do FBSP mostra que apesar da crise econômica os 27 estados brasileiros têm investido mais em Segurança Pública, em face do aumento de 17\% entre 2014 (R\$ 67,3 bilhões) frente a 2013 ( $\mathrm{R} \$ 57,5$ bilhões), com os gastos per capita dos estados alcançando média de R \$ 332,21. Já os 5.570 municípios brasileiros gastaram R \$ 3,9 bilhões com Segurança Pública, e a União foi o ente que alocou menos recursos no setor em 2014 (R \$ 8,1 bilhões). Entretanto, não existem estudos que mostrem correlação direta entre aumento de despesas em Segurança Pública e redução dos homicídios. E o Brasil é o grande exemplo disso, uma vez que gasta o equivalente ao que Alemanha, França e Espanha despendem com Segurança Pública, sem que tais recursos tenham se traduzido em eficiência pública. Ou seja, em geral, os estados brasileiros apresentam um modelo de Política de Segurança Pública dispendiosa (recursos mal geridos) e ineficaz (métodos ultrapassados).

Confirma a argumentação o anuário do FBSP (2015), com a classificação das capitais brasileiras por homicídios (para cada 100 mil habitantes) em 2014:

1. Fortaleza/CE $(77,3)$;

2. Maceió/AL $(69,5)$;

3. São Luís/MA $(69,1)$;

4. Natal/RN $(65,9)$;

5. João Pessoa/PB $(61,6)$;

6. Teresina/PI $(53,2)$;

7. Belém/PA $(51,2)$;

8. Salvador/BA $(48,1)$;

9. Cuiabá/MT $(47,4)$;

10. Aracaju/SE $(47,1)$;

11. Goiânia/GO $(46,7)$;

12. Manaus/AM $(41,6)$;

13. Porto Alegre/RS $(40,6)$;

14. Vitória/ES $(38,3)$;

15. Rio Branco/AC (36,5);

16. Macapá/AP (32,5); 
17. Curitiba/PR $(32,4)$;

18. Recife/PE $(32,0)$;

19. Belo Horizonte/MG (30,8);

20. Porto Velho/RO $(30,6)$;

21. Palmas/TO $(27,9)$;

22. Brasília/DF $(25,8)$;

23. Rio de Janeiro/RJ (20,2);

24. Campo Grande/MS (18,9);

25. Boa Vista/RR (17,5);

26. Florianópolis/SC (16,9);

27. São Paulo/SP $(11,4)$.

Segundo o Mapa da Violência 2014 (WAILSELFISZ: 2014), de 2002 até 2012 foram assassinadas 556 mil pessoas no Brasil, número superior à maioria dos conflitos armados mundiais. A taxa brasileira de homicídios chegou a 29 homicídios para cada 100 mil habitantes, com 56.337 pessoas tendo sido mortas em 2012. Entre 2002 a 2012, ocorreu crescimento dos homicídios em 20 das 27 unidades da Federação, sendo que em 07 delas foi “explosivo": Ceará, Maranhão, Paraíba, Pará, Amazonas, Rio Grande do Norte e Bahia. Todavia, compensando esse crescimento, 07 estados apresentaram quedas: Mato Grosso, Espírito Santo, Mato Grosso do Sul, Rondônia, Pernambuco, Rio de Janeiro e São Paulo.

E de acordo com estudos do Ministério da Justiça (2015), o Ceará foi o $3^{\circ}$ estado com maior taxa de homicídios e o $4^{\circ}$ em números absolutos de assassinatos do Brasil em 2014, numa média de 46,4 homicídios por 100 mil habitantes, com Fortaleza liderando o ranking de assassinatos estaduais com 77 homicídios por 100 mil habitantes. Já o Estudo Global sobre Homicídios 2013 do Escritório das Nações Unidas sobre Drogas e Crime (UNODC) destaca que nos últimos 30 anos aconteceram mudanças na localização do número de homicídios em todo o Brasil. Na medida em que Rio de Janeiro e São Paulo diminuíram suas taxas de homicídios em $29 \%$ e 11\%, respectivamente, Ceará, Paraíba e Bahia tiveram fortes aumentos. O estudo aponta que das 50 cidades que mais matam pessoas no mundo, o Brasil tem 16 urbes neste ranking, com taxas “epidêmicas" que variam entre 33 a 77 mortes por 100 mil habitantes, sendo Fortaleza a $7^{\text {a cidade }}$ mais violenta do mundo. No entanto, de forma absoluta, Fortaleza ocupa o posto de $2^{\text {a }}$ cidade que mais se mata pessoas no planeta, com 2.754 mortes registradas em 2012, ficando atrás apenas de Caracas/Venezuela, que computou 2.760 pessoas assassinadas em 2012. (UNODC: 2014).

Para se ter ideia do descalabro da violência em Fortaleza e no Ceará, em 12 anos ou 144 meses (2002 a 2014), Portugal, que possui população superior (10,5 milhões de habitantes) ao Ceará (8,8 milhões), registrou 619 assassinatos, com o Ceará necessitando 50 dias, e Fortaleza 
somente 90 dias para alcançar igual número de homicídios. Já a taxa de homicídios na França (65,4 milhões de habitantes) em 2013 foi de 1,0 a cada 100 mil habitantes, uma diferença significativa aos índices cearenses no período, que acusou 50,4 casos por 100 mil habitantes. Entre 2002 e 2014, o número de homicídios no Ceará cresceu numa média de $14,5 \%$ ao ano, representando o $2^{\circ}$ pior índice do País nesta taxa de criminalidade. (UNODC: 2014).

O Mapa da Violência 2015 (WAILSELFISZ: 2015) revela que, em dez anos (2002-2012), o número de mortes por armas de fogo quadruplicou no Ceará (287,9\%), com salto de 815 para 3.161 óbitos, e 8,6 assassinatos/dia, com as principais vítimas sendo homens jovens e negros $(5,5)$. Os dados por 100 mil habitantes são igualmente alarmantes: 36,7 mortes em 2012, ou 245\% a mais do que os percentuais $(10,6)$ de dez anos antes. Neste quesito, o Ceará ocupa a $3^{\text {a }}$ colocação no ranking brasileiro, atrás apenas de Alagoas (55 mortes por arma de fogo por 100 mil habitantes) Espírito Santo $(38,3)$. Em 2002, o Ceará ocupava tão somente a $20^{a}$ posição nacional. Tal número é superior à média do Nordeste (31,5 mortes por 100 mil habitantes), e à do Brasil (21,9 mortes por 100 mil habitantes).

E o crescimento é maior considerando-se apenas Fortaleza. Os 399 homicídios de 2002 saltaram para $1.724 \mathrm{dez}$ anos depois (4,7 por dia), com aumento de 332,1\%, e 69 mortes por 100 mil habitantes, colocando a cidade na $2^{\mathrm{a}}$ posição entre as capitais do País em óbitos por arma de fogo, atrás somente de Maceió (79,9). Uma década antes, eram 18 homicídios, sendo o crescimento no período de 283,6\%. Entre pessoas de 15 a 29 anos assassinadas no Ceará em 2012, $60 \%$ eram de Fortaleza (1.204), com 3,3 pessoas mortas para cada dia do ano. Comparando com 2002 (237), o crescimento chegou a 408\% (WAILSELFISZ: 2015). Ao longo de 08 anos (20072014), o numero de Crimes Violentos Letais Intencionais (CVLI) representado pelos homicídios e latrocínios quase triplicou no Ceará, com alta de $184 \%$ e registro de 24.184 assassinatos $(8,2$ mortes/dia), com os gastos estaduais em Segurança Pública tendo aumentado 347\%, de 4,5\% do orçamento ou R $\$ 520$ milhões para 8,9\% ou R \$ 1,8 bilhão. (ATALIBA \& SARQUIS: 2014):

\begin{tabular}{r|rcc|}
\hline \multicolumn{1}{|c|}{ Ano } & Homicídios & Variação & Média/dia \\
\hline 2007 & 1.847 & $18 \%$ & 5,1 \\
\hline 2008 & 1.904 & $3 \%$ & 5,2 \\
2009 & 2.262 & $19 \%$ & 6,2 \\
2010 & 2.803 & $24 \%$ & 7,7 \\
2011 & 2.805 & $0,1 \%$ & 7,7 \\
2012 & 3.729 & $33 \%$ & 10,2 \\
2013 & 4.395 & $18 \%$ & 12,0 \\
2014 & 4.439 & $1 \%$ & 12,1 \\
Total & $\mathbf{2 4 . 1 8 4}$ & $\mathbf{1 8 4 \%}$ & $\mathbf{8 , 2}$ \\
& & & Tabela 01: SSPDS/2015
\end{tabular}


Em 2015, com as mudanças nos comandos do governo estadual e da pasta de Segurança Pública os homicídios tiveram redução de 9,3\% no Ceará. Entretanto, tais índices são menores apenas que a dos anos 2014 (4.439) e 2013 (4.395), sendo superiores a 2013 (3.730) e todos os anos antecedentes. Somente em Fortaleza, com 1.651 homicídios registrados em 2015, matou-se mais pessoas que em todo o Estado do Ceará em 2006, ano imediatamente anterior a explosão nas taxas de homicídios cearenses e em que foram registrados 1.565 assassinatos. (PAIVA: 2016).

Quando um governo amplia seus investimentos financeiros em determinada política pública sem planejamento administrativo, metodologia de aferição concreta de suas ações, integração intersetorial e inclusão de atores essenciais (prefeituras, sociedade civil, empresários, universidades) dificilmente os resultados positivos serão descortinados. Ademais, os custos arcados pelo Ceará com Segurança Pública vinculam-se direta e indiretamente com a saúde, seguridade social, sistema carcerário, medidas socioeducativas e programas de prevenção criminal nas ruas e rodovias. Já os custos bancados pela sociedade e iniciativa privada englobam perdas patrimoniais e de capital humano, custas processuais, gastos com seguros e segurança privada e despesas com serviços médicos. Com tais resultados, caso a Secretaria de Segurança Pública e Defesa Social do Ceará (SSPDS) fosse uma empresa estaria à beira da falência, uma vez que os recursos públicos para a Segurança Pública mais que triplicaram na inteireza temporal dos mandatos do governador Cid Gomes (2007-2014), e as taxas de homicídios cresceram absurdos 184\% em igual período.

Em sociedades como a brasileira, a violência, criminalidade e marginalidade têm causas múltiplas: ineficácia institucional, desigualdade socioeconômica, tráfico de drogas, desagregação familiar, banalização da insegurança por setores da mídia e impunidade. Na Segurança Pública, a Resolução n 34.169/79 da Organização das Nações Unidas (ONU) recomenda a combinação de ações de repressão qualificada, prevenção e reeducação com políticas de desenvolvimento econômico e social, uma vez que a criminalidade crônica é, em igual tempo, causa e consequência da pobreza, insegurança e subdesenvolvimento. No Brasil, mesmo com duas décadas de inclusão socioeconômica de volumosos segmentos menos abastados e aumento dos gastos orçamentários na Segurança Pública, ocorreu um paradoxo com o aumento vertiginoso da violência, em especial, no Nordeste, no Ceará e em Fortaleza, desfazendo a tese de que avanços econômicos para a população e ampliação dos recursos estatais diminuem automaticamente os índices de criminalidade.

\section{DESCRIÇÃO GEOPOLÍTICA DA VIOLÊNCIA, MARGINALIDADE, CRIMINALIDADE}

No século XVII, o filósofo inglês Thomas Hobbes (Leviatã) teorizou que o estado natural dos homens é a guerra, em virtude de todos desejarem as mesmas coisas (liberdade e propriedade), e somente podendo-se adquirir a paz mediante a realização de um pacto social. Tal proposta foi aprofundada no século XVIII pelo pensador suíço Jean Jacques Rousseau (Contrato Social) ao demonstrar que os homens deveriam renunciar parcelas de sua liberdade e propriedade em prol do 
Estado, que passaria a ser o único responsável pela garantia da Segurança Pública e aplicação da Justiça através do "monopólio legítimo da força" em um território jurisdicionado. A sociedade é de fato um contrato entre várias gerações: aqueles que vivem, estão mortos e estão por nascer. Assim, a manutenção da propriedade privada, a defesa das liberdades individuais e a conquista da paz pública concretizam-se com a obediência às leis pelo conjunto da sociedade. (BURKE: 2012).

Em 1916, na tentativa de entender a manifestação do monopólio legítimo da força do Estado num território, o conceito de "geopolítica" foi apresentado pelo jurista sueco Rudolf Kjellén $(O$ Estado como forma de vida), que estabeleceu vínculos teóricos entre aspectos geográficos de um território e acontecimentos político-estatais. A geopolítica foi formulada não somente como relação direta entre território e poder, mas o território como objeto e meio para o próprio exercício do poder de Estado (COSTA: 1992). Objeto de pesquisas da sociologia, geografia, relações internacionais, história, direito, ciência política, psicologia, economia e criminologia, a Geopolítica tornou-se uma frente teórica heterogênea que compreende territorialidade e nuances políticas do Estado-nação no plano externo e nas questões internas (território, povo, poder de jurisdição).

Portanto, a Geopolítica se identifica não apenas com uma única disciplina (geografia, ciência política ou estratégia militar), mas, com uma ampla área interdisciplinar de leituras e observações (VESENTINI: 2005). Enquanto ciência, prática, técnica, arte e/ou disciplina, a Geopolítica concentra-se na análise do poder e das práticas políticas em suas mais variadas manifestações territoriais, tanto nas relações internacionais entre estados, como nos acontecimentos internos de um Estado específico. Em sentido lato, as discussões geopolíticas ocorrem de forma engajada com outras teorias científicas contextualizando os principais temas da conjuntura internacional, nacional, regional e local, abordando desde a globalização, fronteiras no Oriente Médio, política externa americana, comunidade europeia, bolivarismo na América Latina e crescimento econômico chinês, até os temas internos de uma nação como fluxos de mercado, capital intelectual, infraestrutura, produtividade, recursos minerais, problemas socioambientais e níveis de violência.

A Geopolítica busca compreender as realidades vividas, em curso e possíveis (passado, presente e futuro) e interpretar as questões conflituosas que afetam o desenvolvimento político dos estados ou de um dado Estado. Como a dominação plena de um determinado território caracteriza o Poder do Estado e compreende o "direito legítimo de defesa" (plano externo) e o "monopólio legítimo da força" (plano interno), torna-se essencial que os saberes geopolíticos (espaço-tempo, valores sociais, capacidade militar, geografia regional, estatísticas urbanas, economia, demografia, políticas sociais) referenciem as decisões centrais de poder visando à definição das estratégias gerais nas mais diferentes disputas externas (militares) e conflitos internos (policiais). E a forma mais enriquecedora de participar das teorias geopolíticas é observar, conhecer e comunicar-se com o próprio mundo em que se vive, independente da pujança econômica, robustez política das instituições e nível de conflituosidade social no território estatal. (TOSTA: 1984). 
No caso específico da seara "Segurança Pública de Fortaleza/Ceará”, a Geopolítica pode listar os mais diferentes ambientes criminógenos (residências e ruas de bairros periféricos ou não, rodovias, equipamentos públicos e comunitários, instituições públicas, empresas privadas, presídios, centros socioeducativos) e vincular suas análises às condições sociais, econômicas, urbanas e políticas das realidades visando entender cientificamente até que ponto a concepção, planejamento, investimentos e ações da política de Segurança Pública adotada podem prevenir, reprimir e/ou reeducar os autores de fatos sociais eivados de violência, criminalidade e marginalidade. Entretanto, a abordagem das complexas expressões deste "triunvirato funesto" deve ultrapassar o senso comum, explicações simplistas, visões reducionistas e modelos teóricos estereotipados. Os ambientes criminógenos, independente do nível de problemas sociais, econômicos, políticos e urbanos de uma cidade, geram conflitos que atingem direta e indiretamente toda sociedade (medo e anomia social) e contam, muitas vezes, com as contradições da administração pública (equívocos de diagnóstico e erros de investimentos) que não consegue entender, conter ou reverter o quadro de explosão da insegurança pública. (XAVIER: 2015).

A violência pode ser conceituada como o uso excessivo da força, através de comportamentos transgressores, intolerantes e constrangedores que causam danos às pessoas e aos seus patrimônios. Dada sua forte manifestação nas grandes cidades, estes formatos de agressões interpessoais foram convencionalmente denominados de "violência urbana". Tal fenômeno social expresso em diversos tipos de agressão (física ou psíquica) provoca uma gama de lesões e óbitos de pessoas, implicações danosas à propriedade, desintegração das regras de conduta civilizada e deturpação das relações jurídicas e éticas pela anomia social, prejudicando o bem-estar urbano da coletividade. Entretanto, a violência urbana é determinada não apenas por falhas institucionais nas políticas de Segurança Pública e de Justiça assumidas nos diferentes territórios jurisdicionados. A agudeza da violência urbana de Fortaleza (e brasileira) é multicausal, também podendo ser explicada como resultado da adoção pela sociedade de deturpados valores morais, desigualdades sociais, problemas de desordem urbana e discriminadora divisão étnica das relações sociourbanas. (XAVIER: 2015).

Em relação à criminalidade faz-se imperioso realizar sua distinção conceitual do "crime", que envolve toda ação ou omissão antijurídica praticada pelas pessoas enquanto violação das leis penais por se constituir em ofensa, dano ou perigo ao conjunto de bens individuais ou coletivos, os quais, o Estado procura evitar pela definição de punibilidades específicas. A criminalidade resulta da somatória (alta, média ou baixa) dos diferentes crimes praticados pelas pessoas de um determinado lugar e durante certo período (espaço-tempo). Ou seja, a criminalidade é o conjunto de fatos antijurídicos que contrariam de forma gravosa as condições existenciais da vida social. Assim, mesmo que o nível de crimes possa ser diminuído para patamares inexpressivos em uma dada sociedade, a criminalidade, como possibilidade dos indivíduos em dado espaço-tempo 
praticar atos delituosos (dolosos ou não) jamais deixará de existir socialmente. (XAVIER: 2015).

A marginalidade explica as ações das pessoas situadas nos limites ou fora das margens dos sistemas institucionais aceitos pela maioria da sociedade, independente do extrato socioeconômico a que pertençam. A marginalidade atenta contra as regras jurídicas postas por atos de "paralelismo" à ordem estatal e padrões sociais: desordem, vandalismo e/ou delinquência. Os conflitos resultantes dessa "manifestação marginal” eivada de insatisfação jurídico-institucional, impotência econômica e identidade social sem autoestima, geralmente, são expressos em atitudes de agressão ao patrimônio público e à propriedade privada (com ou sem dolo/violência), mas que implicam no aumento dos índices de criminalidade. Embora a marginalidade represente um fenômeno social gestado por contradições sociais, econômicas e urbanas ocorrendo, predominantemente, via autoprojeção psicológica, sobrevivência econômica, expressão subcultural ou mobilidade social, é fato inconteste que prejudica a ordem social e quebra as regras jurídicas, acomodando-se como problema policial afeito às soluções preventivas e repressivas. (XAVIER: 2012).

Medo pode ser conceituado como uma perturbação angustiosa perante um risco ou uma ameaça real ou imaginária. Também se refere ao receio que alguém tem de que venha a acontecer algo contrário àquilo que pretende. $\mathrm{O}$ medo é uma emoção primária que se caracteriza por um sentimento desagradável e provocado pela percepção de um perigo, seja ele presente ou futuro, real ou suposto. Relativamente ao aspecto social e cultural, o medo faz parte do caráter de uma pessoa ou do imaginário coletivo de uma organização social (WINNICOTT: 1984). Já a anomia é o conjunto de situações resultantes da degradação de normas sociais. Sociologicamente, anomia é a incapacidade da estrutura social em proporcionar a certas pessoas o que precisam para superarem seus desafios sociais. A anomia diz respeito a desvio das normas sociais, mas não das leis: quando alguém desobedece às leis, está a cometer um delito. Os grupos socioeconômicos menos favorecidos são os que sofrem maior pressão, o que os leva ao desvio das normas sociais e fomenta o colapso de governabilidade por não se conseguir entender e controlar situações de alienação experimentada por indivíduos ou subculturas. A anomia resulta da dissociação entre os fins culturais (desejos dos membros da sociedade), as normas que determinam os meios para permitir que os indivíduos tenham acesso a esses fins e a repartição existente desses meios necessários. E a ruptura social tem lugar quando a relação entre meios e fins se debilita. (MERTON: 1970).

Contemporaneamente, como o Estado brasileiro fracassou na sua missão pacificadora, o “estado natural do homem" ressurge através do medo e anomia social com a violência, criminalidade e marginalidade ampliando entre diversos segmentos da sociedade e afetando a economia e a paz social. O descrédito nas políticas de Segurança Pública e Justiça e no Poder Judiciário toma assento no inconsciente coletivo das pessoas vitimadas pelo crime, trazendo como consequências o acirramento da sensação de insegurança, a incredulidade na punibilidade institucional, a baixa perspectiva de ressocialização prisional, a ampliação de sentimentos de 
vingança imediata e o rompimento dos pilares civilizatórios do Contrato Social, inclusive, com a retomada de preceitos do Código de Hamurabi (1.780 a. C): "fazer justiça com as próprias mãos".

Entre 2007-2014, Fortaleza vivenciou quase um retorno ao "estado de natureza" causando medo e anomia social, aumentando a violência, criminalidade e marginalidade e generalizando a sensação de insegurança. A Segurança Pública enquanto "política-fenômeno" necessita de concepção moderna, plano de longo prazo, novos atores e ações em diversas frentes visando entender as causas multifatoriais da violência e intervir em seu complexo quadro de manifestação social. Portanto, o aumento exponencial dos CVLI em Fortaleza (e no Ceará) no período referido não é "atípico", mas, resultado previsível em face da doutrina arcaica, políticas experimentalistas, recursos mal gastos e quadro de desigualdade social.

E como o estudo das manifestações criminais nos territórios citadinos requer a análise geopolítica, a visibilidade juvenil, a divisão de responsabilidades institucionais e, em especial, o medo e anomia social, são as categorias geopolíticas eleitas para entender tal périplo histórico da Segurança Pública em Fortaleza.

\section{PRODUÇÃO DA VIOLÊNCIA CONCENTRADA E SENSAÇÃO DE INSEGURANÇA PELO MEDO E ANOMIA SOCIAL}

Os números abismais de homicídios no Ceará entre 2007-2014 representam que a concepção doutrinária de Segurança Pública adotada não envolveu em sua formulação a análise dos fatores geopolíticos de produção da criminalidade, combatendo tão somente o criminoso de forma imediata e em certos lugares, legitimando a violência institucional e transmitindo uma momentânea sensação social de segurança, tornando-se ineficaz em face da perpetuação de "ambientes criminógenos" advindos do estoque de problemas urbanos e do acirramento das desigualdades socioeconômicas em Fortaleza e outras cidades da Região Metropolitana e interioranas.

Para o sociólogo polonês Zygmunt Bauman (2009) estar seguro implica enxergar o outro como semelhante. A despeito de todo o aparato bélico à disposição das grandes cidades, o indivíduo se sente permanentemente inseguro, ameaçado e amedrontado, mais inclinado ao pânico e interessado em qualquer coisa que tenha a ver com tranquilidade e segurança. E o medo é um problema de confiança social. Contemporaneamente, a face mais visível do medo em Fortaleza não é expressa somente na quantidade de homicídios, mas também na arquitetura defensiva da "cidade de muros" representada por grades nas fachadas residenciais; diversificada oferta de serviços intramuros (cercas elétricas, guaritas, interfones e apetrechos anti-pânico) a serviço da clausura dos condomínios; seguranças e aparatos tecnológicos de proteção nas empresas; e som metálico das travas das portas dos carros nas ruas, com ou sem flanelinhas. (ARAÚJO: 2015). 
Conforme a Pesquisa Nacional de Vitimização do Ministério da Justiça (2013), mais de 60\% da população de Fortaleza teme ser assaltada; 47\% sente-se insegura ao andar nas ruas; e 83\% afirmou ter notado aumento da criminalidade nos 12 meses anteriores à pesquisa. Dentre 346 grandes municípios brasileiros pesquisados, Fortaleza ficou com a $3^{\mathrm{a}}$ colocação nacional nos três índices citados, e também como a $4^{\mathrm{a}}$ cidade com maior número de pessoas que sofreram ações violentas, sendo que 40,5\% dos entrevistados afirmou ter passado por algum tipo de agressão na vida e 31,5\% respondeu ter sido vítima recente de violência (agressão física, discriminação, fraude, estelionato, acidente de trânsito, furto/roubo, ofensa sexual e sequestros-relâmpago).

Uma prática cotidiana que agrava o círculo vicioso da criminalidade e a sensação social de insegurança pode ser debitada em setores da mídia que realizam numa abordagem sensacionalista a ampla difusão da violência. O enfoque comunicacional é quase sempre amparado na institucionalidade repressiva (contra-violência) e punição capital (pena de morte e prisão perpétua), sem considerar fatores sociais, econômicos, urbanos de produção da criminalidade. Na verdade, existe uma relação vantajosa para tais setores da mídia. O "conteúdo de medo" dos programas policiais transforma-se em forte audiência, conquista contas de anunciantes e implica em cargos políticos para seus apresentadores. E os resultados desta formação da opinião pública indicam que boa parte da população considera os meios de proteção privada, a contra-violência e as leis severas como formas eficazes para atender as agruras da Segurança Pública (XAVIER, 2012). Não é sem razão que Fortaleza restou geopoliticamente configurada pelo medo e anomia social.

De acordo com a pesquisa Síntese de Indicadores Sociais 2013 do IBGE (2014), o Ceará lidera a sensação de insegurança no Nordeste. E quem tem poder aquisitivo contrata serviços e adquire apetrechos de segurança privada, segmento que cresce cerca de $8 \%$ ao ano e oferece 16 tipos de atendimento para suprir necessidades de segurança das repartições públicas, condomínios, estabelecimentos comerciais e bancários, veículos e pessoais. Conforme dados do Sindicato das Empresas de Segurança Privada do Ceará (SINDESP), em 2010, havia 5.362 vigilantes em atividade no Ceará. Já em 2015, o setor ampliou 524\% com 33.479 vigilantes profissionais em atividade. O número é 93\% superior ao efetivo da Polícia Militar (17.341 agentes) e 1.131\% maior que o da Polícia Civil (2.719 profissionais). Contudo, a Polícia Federal, que autoriza as empresas privadas de segurança, estima que para cada profissional autorizado trabalhando existam outros três ilegais, ou seja, algo em torno de 101 mil vigilantes clandestinos no Ceará. (XAVIER: 2015).

A "geopolítica do medo e anomia social" se expressa pela violência em certos espaços urbanos e a estigmatização imediata dessas áreas, principalmente, as referentes ao turismo, um dos principais vetores da economia de Fortaleza, implicando em menos empreendimentos e investimentos, e consequentemente, na diminuição de recursos, oportunidades de clientes e visitantes, emprego e renda e arrecadação tributária. Outros efeitos nocivos são: perpetuação dos ambientes criminógenos, atitudes corriqueiras de instilação do ódio como resposta às frustrações de 
toda ordem; e realização de "justiça com as próprias mãos" através de linchamentos de bandidos flagrados cometendo crimes (ou de meros suspeitos). As redes sociais que realizam uma positiva interligação entre pessoas, comunidades e movimentos sociais também mostram uma faceta obscura ao canalizarem ressentimentos, discriminações e preconceitos. Agrava-se o quadro de incivilidade quando certos formadores de opinião pública no afã de denunciar a omissão do Estado favorecem reações multitudinárias de quebra da ordem pública e de contra-violência institucional.

A geopolítica do medo e anomia social acarreta o desprezo à lei e suas punições, a instauração de regras sociais particulares, o estado de incerteza acerca do comportamento do outro em dadas situações do cotidiano e em diferentes territórios urbanos e leva indivíduos à criminalidade, atitude de natureza autoritária e letal, mas que oferta o que lhes falta: dinheiro, poder e visibilidade. A geopolítica do medo e anomia social também democratiza a sensação de insegurança em todos os segmentos da população e altera de diversas formas as rotinas, hábitos, autonomias, costumes, roteiros e percursos dos moradores das médias e grandes cidades, uma vez que a liberdade pessoal passa a ser edificada em torno do medo, regulada por dispositivos de segurança privada e calculada pela possibilidade do cidadão vir a sofrer uma ação violenta. $\mathrm{Na}$ medida em que as pessoas vão sendo vítimas e têm histórias para contar sobre a violência, estas nefastas experiências narradas repercutem no cotidiano de um número cada vez maior de segmentos sociais, deixando as pessoas receosas diante de situações simples do cotidiano, como parar os carros em semáforos, viajar em estradas, passear a noite no quarteirão ou dormir sozinhas.

E o medo da violência (difusa ou concentrada) passa a orientar tanto a pressão dos cidadãos em relação às autoridades públicas, como o comportamento coletivo dos consumidores, mudando padrões de confiança dos investimentos dos empreendedores em relação aos espaços urbanos e alterando suas valorizações econômicas, como é o caso da queda dos preços dos imóveis e o esvaziamento de lugares de consumo (bares, restaurantes, lojas comerciais). A violência é considerada difusa quando aflora a possibilidade de qualquer pessoa ser vítima, independente do lugar e horário em que se encontre. Já a violência concentrada tem como vítima preferencial o jovem de sexo masculino, negro, de baixa renda, pouca formação escolar e morador de periferia urbana, com sua vulnerabilidade verificada pela exposição rotineira deste segmento às práticas de risco: vivencia situações palpáveis de criminalidade, envolve-se mais em conflitos e resolve suas disputas interpessoais pelo confronto entre grupos rivais territoriais ("geopolítica da visibilidade juvenil”). De sorte, que quando não sente o Estado próximo e apto para intervir eficazmente em relação à violência difusa ou concentrada, a população passa a ansiar por soluções simplistas e imediatas para os problemas de Segurança Pública e Justiça.

A geopolítica do medo e da anomia social explica que a violência, criminalidade e marginalidade têm aprisionado as pessoas numa "arquitetura da segurança" inserida na "cidade dos 
muros", representando a quebra da sociabilidade de extratos da população, até mesmo entre os mais próximos territorialmente: os vizinhos. A ausência estatal nas regiões que mais demandam estrutura urbana adequada e políticas públicas (trabalho, cultura, esporte, lazer, educação) e o quadro de desigualdade social representam a derrota generalizada do Estado e da sociedade que em muito contribui para o aumento da criminalidade em Fortaleza e nas médias cidades cearenses. E a desigualdade social é um fator mais explicativo da violência endêmica do que a pobreza, tendo em vista que a desigualdade social revela-se pela distância que certos segmentos ocupam em relação a outros mais abastados economicamente. A violência urbana tem um viés de classe, de gênero e etário, na medida em que vitimiza, preferencialmente, as populações de territórios considerados hierárquica e simbolicamente como "desclassificados urbanisticamente", e ataca mais os jovens, negros, moradores de periferias, de baixa renda e pouca formação educacional. (XAVIER: 2012).

Outro aspecto identificado na geopolítica do medo e anomia social é o "fator de criminalidade 80/20", ou seja, até $80 \%$ dos homicídios ocorre em raios de abrangência de cerca de $20 \%$ do território de uma cidade, em especial, nas favelas e bairros periféricos com carência urbana, desigualdade socioeconômica e ausência de políticas públicas. Tais estudos de territorialidade criminal apontam para o surgimento de regiões denominadas de "cinturão vermelho da criminalidade", áreas geralmente fora das zonas nobres das cidades, e que recebem uma presença constante de patrulhamento de policiais, mas, quase sempre não tem o beneplácito de outras pastas governamentais estaduais e municipais, como educação, saúde, esporte, lazer, emprego e renda, mulher, juventude, urbanismo, meio ambiente, infraestrutura e mobilidade urbana. Dos 678 raios de abrangência dos homicídios ocorridos em Fortaleza, em 2013, constatouse a existência de 243 favelas (35,84\%) presentes em seus entornos. (IPECE: 2014).

Corrobora a argumentação, a pesquisa realizada pelo Núcleo de Estudos da Violência da Universidade de São Paulo (NEV/USP), em 2012, constatando que o maior percentual de pessoas que se sentem inseguras figura na classe A (72\%), a mais abastada, com os índices na classe E (fatia mais pobre da população) caindo para 44\%, e levando a crer que tais segmentos estão "acostumados" com a situação de alto perigo em face do império da violência em suas áreas de moradia periféricas (NEV/USP: 2012). Todavia, tais dados refletem que a sensação de insegurança atinge a maioria da sociedade, mesmo que percebida diferentemente pelos vários extratos sociais.

Diante desse quadro geopolítico caótico de medo e anomia social que se abateu sobre as grandes cidades brasileiras, em especial, Fortaleza, nos últimos dez anos, e constatado que a violência atinge mais os jovens, negros, moradores de periferias, de baixa renda e pouca formação educacional (os que mais matam e morrem), verifica-se a necessidade de uma mudança na concepção da Política da Segurança Pública cearense (e brasileira) via adoção de estudos referentes à "geopolítica da divisão de responsabilidades institucionais", a exemplo de experiências bem sucedidas de cidades estrangeiras (Nova York, Chicago, Los Angeles, Cáli, Medelín, Bologna e Barcelona) e estados pátrios (São Paulo, Minas Gerais, Rio de Janeiro, Pernambuco e Paraná). 
A geopolítica da divisão de responsabilidades institucionais advoga a participação de diferentes entes públicos (pastas estaduais e municipais de políticas sociais) e inclui novos atores sociais (empresas, entidades da sociedade civil, Organizações Não Governamentais) visando potencializar programas preventivos e reeducadores de curto, médio e longo prazo e largo alcance (esportes e artes, escolas e cursos profissionalizantes, habilitação para o mercado de trabalho) que afastem os jovens de sua "geopolítica da visibilidade juvenil" pela violência, criminalidade e marginalidade. Tais ações compartilhadas (estatais/sociais) devem ter como contrapartida o conhecimento de direitos e deveres destes jovens para com a sociedade objetivando construir a paz social por meio de mudanças comportamentais a curto e médio prazo. Quanto mais cedo chega a eficiente presença do Estado nos territórios vulneráveis e a sociedade toma atitudes que fazem diferença para as expectativas da juventude, menores serão as possibilidades de um jovem ingressar nas raias da violência, criminalidade ou marginalidade.

\section{CONSIDERAÇÕES FINAIS}

A simbologia geopolítica de Fortaleza permanece inalterada com seus canhões continuando apontados para a cidade até o presente. Canhões reais e imaginários que segregam socialmente a maioria da população e vitimizam preferencialmente os homens jovens, negros, pobres, de baixa renda, pouca formação educacional e moradores das periferias. Assim, indaga-se: Fortaleza conseguirá se reconciliar com o espaço público e destruirá os seus canhões reais e imaginários, deixando para trás a herança de cidade fortificada em que poderosos se erguiam enclaves contra a fúria nativa ou estará condenada ao retrato doente de uma metrópole refugiada no próprio medo?

Vale salientar neste questionamento final que o aumento dos homicídios em Fortaleza e no Ceará é fato inconteste e acompanha uma tendência verificada no Brasil enquanto uma das nações mais violentas do mundo, apesar dos avanços institucionais de redução dos CVLI conquistados por outros estados. Na verdade, a atuação da Segurança Pública pretendida por amplos setores sociais e aceita como padrão institucional reduz-se a repressão policial dirigida aos criminosos contumazes, e por preconceito, aos segmentos sociais mais jovens e vulneráveis das periferias. E no Ceará, entre 2007-2014, o orçamento da Segurança Pública mais que triplicou, e inversamente, as taxas de homicídios cresceram 184\%, com Fortaleza tornando-se uma das cidades mais violentas do planeta. Ou seja, com tal doutrina arcaica de Segurança Pública e desastrosos resultados, caso a SSPDS fosse uma empresa estaria à beira da falência. Mesmo paradoxo ocorreu no Brasil, nos últimos vinte anos, com o crescimento dos homicídios desfazendo a tese que avanços econômicos e ampliação de recursos financeiros estatais diminuem automaticamente a criminalidade.

A recomendação da ONU sobre a "política-fenômeno" de Segurança Pública combina prevenção, reeducação e repressão qualificada do crime com políticas de desenvolvimento 
socioeconômico e intervenções urbanas, uma vez que a criminalidade crônica é, ao mesmo tempo, causa e consequência da pobreza e insegurança. Portanto, com a ausência das análises geopolíticas, as causas explicativas, os fatores incidentes e as circunstâncias postas que desencadeiam os problemas de insegurança permanecem intactos nas comunidades objeto da atuação policial repressiva, com a violência espalhando-se pela cidade e ampliando os raios das atitudes marginais e a somatória dos crimes. Até porque o atual quadro de desigualdade e violência de Fortaleza inclina-se para a máxima asseverada no século XVII pelo filósofo inglês Francis Bacon: Nada provoca mais danos num Estado do que homens astutos a quererem se passar por sábios.

\section{REFERÊNCIAS}

ARAÚJO. Henrique. Nossos canhões imaginários. O Povo. Fortaleza, 13. abr. 2015. Fortaleza: a cidade e o devir, p. 12-14.

ATALIBA, Flávio \& SARQUIS, Adriano. Desenvolvimento econômico do Ceará: evidências recentes e reflexões. Fortaleza: IPECE, 2014.

BAUMAN, Zygmunt. Confiança e medo na cidade. Rio de Janeiro: Zahar, 2009.

BURKE, Edmund. Reflexões sobre a revolução na França. Rio de Janeiro: Topbooks, 2012.

COSTA, Wanderley Messias. Geografia política e geopolítica. Discurso sobre o território e o poder. São Paulo: Edusp, 1992.

ESCRITÓRIO DAS NAÇÕES UNIDAS SOBRE DROGAS E CRIMES. Relatório global de homicídios 2013. Londres: UNODC, 2014. Disponível em: http:///www.unodc.org/brazil>. Acesso em: 18 nov. 2015.

FORUM BRASILEIRO DE SEGURANÇA PÚBLICA. Anuário brasileiro de segurança pública. $9^{\mathrm{a}}$ ed. São Paulo: FBSP, 2015.

INSTITUTO BRASILEIRO DE GEOGRAFIA E ESTATÍSTICA. Estimativa do Censo 2014. Brasília: IBGE, 2014. Disponível em: http:///www.ibge.gov.br>. Acesso em: 14 dez. 2015.

INSTITUTO BRASILEIRO DE GEOGRAFIA E ESTATÍSTICA. Síntese de indicadores sociais

2013. Brasília: IBGE, 2014. Disponível em: http:///www.ibge.gov.br>. Acesso em: 22 dez. 2015. 
INSTITUTO DE PESQUISA E ESTRATETÉGIA ECONÔMICA DO CEARÁ. Anuário estatístico do Ceará 2013. Fortaleza: IPECE, 2014. Disponível em: http:///www.ipece.ce.gov.br>. Acesso em: 24 out. 2015.

MERTON, Robert. Sociologia, teoria e estrutura. São Paulo: Mestre Jou, 1970.

MINISTÉRIO DA JUSTIÇA. Diagnóstico dos homicídios no Brasil: subsídios para o Pacto Nacional pela Redução de Homicídios da Secretaria Nacional de Segurança Pública. Brasília: SENASP, 2015.

MINISTÉRIO DA JUSTIÇA. Pesquisa nacional de vitimização. Brasília: SENASP, 2014. Disponível em: http:///www.portal.mj.gov.br>. Acesso em: 28 dez. 2015.

NÚCLEO DE ESTUDOS DA VIOLÊNCIA DA UNIVERSIDADE DE SÃO PAULO. Pesquisa nacional por amostragem domiciliar sobre atitudes, normas culturais e valores em relação à violação de direitos humanos e violência: um estudo em 11 capitais de Estado. São Paulo: NEV/USP, 2012. Disponível em: http:///www.nevusp.org>. Acesso em: 30 dez. 2015.

ORGANIZAÇÃO MUNDIAL DE SAÚDE. Relatório mundial sobre violência e saúde 2013. Genebra: OMS, 2014. Disponível em: https:///www.pt.scribd.com>. Acesso em: 18 dez. 2015. PAIVA, Thiago. Redução das mortes no Ceará em 2015. O Povo. Fortaleza, 12 jan. 2016. Cotidiano, p. 4.

PROGRAMA DAS NAÇÕES UNIDAS PARA O DESENVOLVIMENTO. Atlas do desenvolvimento humano no Brasil 2013. Brasília: PNUD, 2014.

SEN, Amartya. Desigualdade reexaminada. Rio de Janeiro: Record, 2001.

TOSTA, Octávio. Teorias geopolíticas. Rio de Janeiro: Biblioteca do Exército, 1984.

UNITED NATIONS HUMAN SETTLEMENTS PROGRAMME. State of the world's cities 2010/2011: bridging the urban divide. Nairobi: UN Habitat, 2011. Disponível em: https:///www.sustainabledevelopment.un.org>. Acesso em: 24 dez. 2015.

VESENTINI, José William. Novas geopolíticas. São Paulo: Contexto, 2005. 
WAILSELFISZ, Julio Jacobo. Mapa da violência 2014. Homicídios e violência no Brasil. Disponível em: http:///www.mapadaviolencia.org.br>. Acesso em: 24 nov. 2015.

WAILSELFISZ, Julio Jacobo. Mapa da violência 2015. Mortes matadas por armas de fogo. Disponível em: http:///www.mapadaviolencia.org.br>. Acesso em: 15 dez. 2015.

WINNICOTT, Donald Woods. Privação e delinquência. São Paulo: Martins Fontes, 1984.

XAVIER, Laécio Noronha. Políticas públicas de segurança. Fortaleza: LCR, 2012.

XAVIER, Laécio Noronha. Geopolítica da violência urbana. Diagnóstico multifacetado e propostas sistêmicas para a segurança pública do Ceará. Fortaleza: Rodar, 2015. 